Berliner and Rüter also used a resonance method. Astin developed and used a method employing voltage resonance that was subsequently adopted by Akerlöf. The values reported by Harrington were obtained by means of a bridge method at $1 \mathrm{mc}$, and it is uncertain what method Kistler used at $2.1 \mathrm{mc}$. The measurements of Furth $(400 \mathrm{mc})$ and others [19 to 27] were made at very high frequencies, so the low values reported are undoubtedly attributable to anomalous dispersion and are not comparable to static values.

Consideration of the data available on static values suggests that the major descrepancies in the values reported are in large part due to high conductivity as, in general, it appears that precautions have not been taken to obtain and maintain low conductivities for these solutions. To a lesser extent it is also probable that frequency-dependent errors are associated with many of these values. The extent to which these factors may modify the suitability of a method of measurement is exemplified by Kniekamp's [9] study and Hartshorn's analysis [30] of resonance methods.

\section{References}

[1] E. Berliner and R. Rüter, Kolloid-Z. 47, 251 (1929).

[2] R. Furth, Ann. Physik. 70, 63 (1923).

[3] G. Kreinina, J. Exptl. Theoret. Phys. (USSR) 15, 208 (1945).

[4] G. Akerlöf, J. Am. Chem. Soc. 54, 4125 (1932).
[5] A. V. Astin, Phys. Rev. 34, 300 (1929).

[6] E. Berliner and R. Rüter, Kolloid-Z. 47, 251 (1929).

[7] E. H. Harrington, Phys. Rev. 8, 581 (1916).

[8] S. S. Kistler, J. Phys. Chem. 35, 815 (1931).

[9] H. Kniekamp, Z. Physik 51, 95 (1928).

[10] L. Kockel, Ann. Physik 78, 417 (1925).

[11] E. Landt, Centr. Zuckerind. 44, 723 (1936).

[12] R. T. Lattey, Phil. Mag. 41, 829 (1921).

[13] R. T. Lattey, O. Gatty, and W. G. Davies, Phil. Mag. 12, 1019 (1931).

[14] H. Possner, Ann. Physik 6, 815 (1930).

[15] G. Scatchard, J. Am. Chem. Soc. 48, 2026 (1926).

[16] C. Schreck, Physik. Z. 37, 156 (1936).

[17] K. E. Slevogt, Ann. Physik. 36, 141 (1939).

[18] P. Walden and O. Werner, Z. physik. Chem. 129, 405 (1928).

[19] M. Von Ardenene, O. Groos, and G. Otterbein, Physik. Z. 37, 533 (1936).

[20] W. Dahms, Ann. Physik 26, 177 (1936).

[21] O. Dobenecker, Ann. Physik 17, 699 (1933).

[22] P. Drude, Z. physik. Chem. 23, 267 (1897).

[23] A. Duebner, Ann. Physik 84, 429 (1927).

[24] R. Furth, Ann. Physik 70, 63 (1923).

[25] R. Keller, Kolloid-Z. 29, 193 (1921).

[26] G. Kreinina, J. Exptl. Theoret. Phys. (USSR) 15, 208 (1945).

[27] P. Wenk, Ann. Physik 17, 679 (1933).

[28] A. A. Maryott, J. Research NBS 38, 527 (1947) RP1794.

[29] J. Wyman, Phys. Rev. 35, 623 (1930).

[30] L. Hartshorn, Radio frequency measurements by bridge and resonance methods (John Wiley \& Sons, Inc., New York, N. Y., 1940).

Washington, April 13, 1950

\title{
Response of Accelerometers to Transient Accelerations
}

\author{
By Samuel Levy and Wilhelmina D. Kroll
}

\begin{abstract}
Curves and tables are shown for the response of accelerometers to transient exciting accelerations. Three types of acceleration-time relations are considered. When plotted, they have square, triangular, and half-sine-wave shapes. The natural periods of the accelerometers for which the computations were made were approximately one, one-third, and one-fifth of the duration of the acceleration pulse. The damping coefficients of the accelerometers were $0,0.4,0.7$, and 1.0 times the critical values. It is indicated that, to obtain an accuracy of better than 5 percent of the peak acceleration in measuring acceleration pulses having the general characteristics of the triangular or sinusoidal pulses, an accelerometer must have a natural period of about one-third the duration of the acceleration pulse, and a damping constant of about 0.4 to 0.7 of the critical value.
\end{abstract}

\section{Introduction}

Accelerometers are widely used to measure oscillatory and transient vibrations.

The fidelity with which these instruments respond in the case of oscillatory stimuli has been thoroughly studied [1, pp. 61 to 70$]$. It is found that, when the damping is between 0.6 and 0.7 of the critical value and the natural period of the accelerometer is less than about half of the period of the applied acceleration, the accuracy is satisfactory.

In the case of excitation of the accelerometer by a transient vibration, only scattered information is available regarding the reliability of the response obtained. Weiss [2] gives the response to a tri- angular pulse of acceleration for an accelerometer whose natural period is 0.3 the duration of the pulse and whose damping is $0,0.3$, and 0.7 of the critical value. He also gives the response to a suddenly applied constant acceleration for accelerometers with a damping ratio of $0,0.3,0.7$, and 1.0 times the critical value. Welch [3] has determined, on the Westinghouse transient analyzer, the response to several kinds of impulses of a $50 \mathrm{c} / \mathrm{s}$ single-degree-offreedom shock measuring instrument having various amounts of damping. On the basis of these scattered data, and information for undamped accelerometers derived by Frankland [4], Biot and Bisplinghoff [5], and others, it has been common practice to assume that an accelerometer will be acceptable in a given 
application if its damping is 0.6 to 0.7 of the critical value and if its natural period is less than about half of the duration of the acceleration pulse.

The curves presented in this report were computed to obtain more systematic information regarding the accuracy of damped accelerometers in measuring transient phenomena.

\section{Theory}

The usual accelerometer is a single-degree-of-freedom mechanical system. Such a system is shown in figure 1. Means are provided to indicate the relative motion $x$ of the internal mass with respect to the frame. This relative motion is taken as a measure of the acceleration, $d^{2} y / d t^{2}$, of the frame. is

The equation of motion for the mass $m$, figure 1 ,

$$
m \frac{d^{2} z}{d t^{2}}+c\left(\frac{d z}{d t}-\frac{d y}{d t}\right)+k(z-y)=0 .
$$

With

$$
z=x+y,
$$

eq 1 becomes

$$
\begin{gathered}
m \frac{d^{2} x}{d t^{2}}+c \frac{d x}{d t}+k x=-m \frac{d^{2} y}{d t^{2}}, \\
\frac{d^{2} x}{d t^{2}}+\frac{c}{m} \frac{d x}{d t}+\frac{k}{m} x=-\frac{d^{2} y}{d t^{2}} .
\end{gathered}
$$

We wish to know how faithfully the response $x$ of the accelerometer reproduces the time history of the applied acceleration $d^{2} y / d t^{2}$ for pulses of acceleration of finite duration and arbitrary shape. To give the analysis a wider range of usefulness, eq 4 is written in dimensionless form by making the following substitutions:

$$
\left.\begin{array}{l}
a=\left(\frac{d^{2} y}{d t^{2}}\right) /\left(\frac{d^{2} y}{d t^{2}}\right)_{\max } \\
\tau=t / T \\
\xi=-k x / m\left(\frac{d^{2} y}{d t^{2}}\right)_{\max } \\
D=c / 2 \sqrt{m k}=c / c_{c} \\
R=2 \pi \sqrt{m / k} / T
\end{array}\right\}
$$

where

$$
c_{c}=2 \sqrt{m k} \text {, critical value of damping co- }
$$
efficient,
$T=$ duration of acceleration pulse to be measured,

$\overline{2 \pi} \sqrt{m / k}=$ "undamped" period of accelerometer, $\left(\frac{d^{2} y}{d t^{2}}\right)_{\max }=$ peak value of acceleration.
Substituting eq 5 into eq 4 gives

$$
\left(\frac{R}{2 \pi}\right)^{2} \frac{d^{2} \xi}{d \tau^{2}}+\frac{R D}{\pi} \frac{d \xi}{d \tau}+\xi=a .
$$

For a relatively high frequency accelerometer, $R$ is a small number. Under these circumstances, the first two terms in eq 6 become negligible, and the dimensionless response $\xi$ is equal to the dimensionless acceleration $a$. As $R$ becomes larger, the first and second terms start to have an effect. The primary effect of the second term is to introduce a time lag between the response $\xi$ and the acceleration a. The primary effect of the first term is to tend to make the response $\xi$ oscillate in value above and below the value of the acceleration $a$.

\section{Results}

Equation 6, giving the relation between the dimensionless responses $\xi$ and the dimensionless acceleration $a$, was integrated numerically for three values of the natural period ratio having approximately the values, $R=1,1 / 3,1 / 5$; for four values of the damping ratio, $D=0,0.4,0.7,1.0$; and for the three time-histories of acceleration pulse shown in figure 2. Numerical integration, instead of direct integration, was used to give results that could be plotted directly. Small variations from the nominal values of $R$ were used for convenience in computing. These values of $R$ are given in table 1 . A spot check of the results was made using the analytical solution of eq 6 .

The numerical integration was carried out using a time increment of $1 /(20 \pi)$ times the natural period of the accelerometer. Eight decimal figures were used in the computation.

The results are plotted in figures 3 to 11 . Figures 3,4 , and 5 give the response to a sinusoidal pulse of acceleration. Figure 3 gives the response when the natural period is about equal to the duration of the acceleration pulse. Figures 4 and 5 give similar results with the natural period about one-third and one-fifth, respectively, of the duration of the acceleration pulse. In each figure, the dimensionless applied acceleration, $a$, is shown by a dotted line; the response, $\xi$, with the damping ratio $D=0$ by curve 1 ; with $D=0.4$ by curve 2 ; with $D=0.7$ by curve 3 ; and with $D=1.0$ by curve 4 .

Figures 6,7 , and 8 show the response to a triangular pulse of acceleration, and figures 9, 10, and 11 show the response to a rectangular pulse. In each figure, the set of curves brings out the effect of varying only the damping ratio $D$.

\section{Discussion}

It is evident from an inspection of the figures that for none of the accelerometers considered does the time history of the dimensionless response $\xi$ coincide with the time history of the dimensionless accelera- 
TABLE 1.-Errorf or accelerometers and acceleration pulses considered

\begin{tabular}{|c|c|c|c|c|c|c|c|}
\hline (1) & (2) & (3) & (4) & (5) & (6) & (7) & (8) \\
\hline \multirow[b]{2}{*}{$R$} & \multirow[b]{2}{*}{$D$} & \multicolumn{3}{|c|}{ Error } & \multirow[b]{2}{*}{$\Delta \tau$} & \multicolumn{2}{|c|}{ Plotted } \\
\hline & & $\xi_{\max }-a_{\max }$ & $|\xi-a|_{\max }$ & $\begin{array}{l}\text { After shift } \\
|\xi-a|_{\text {max }}\end{array}$ & & $\begin{array}{l}\text { Fig- } \\
\text { ure }\end{array}$ & Curve \\
\hline \multicolumn{8}{|c|}{ HALF-SINE-WAVE PULSE } \\
\hline $\begin{array}{r}1.014 \\
1.014 \\
1.014 \\
1.014 \\
0.338 \\
.338 \\
.338 \\
.338 \\
.203 \\
.203 \\
.203 \\
.203\end{array}$ & $\begin{array}{r}0 \\
0.4 \\
.7 \\
1.0 \\
0 \\
0.4 \\
.7 \\
1.0 \\
0 \\
0.4 \\
.7 \\
1.0\end{array}$ & $\begin{array}{r}0.74 \\
.15 \\
-.05 \\
-.18 \\
.17 \\
.02 \\
.00 \\
-.03 \\
.10 \\
.07 \\
.00 \\
-.01\end{array}$ & $\begin{array}{r}1.36 \\
0.62 \\
.67 \\
.65 \\
.35 \\
.20 \\
.24 \\
.32 \\
.20 \\
.12 \\
.15 \\
.20\end{array}$ & $\begin{array}{r}1.36 \\
0.24 \\
.18 \\
.24 \\
.35 \\
.06 \\
.06 \\
.10 \\
.20 \\
.05 \\
.03 \\
.06\end{array}$ & $\begin{array}{r}0.17 \\
.22 \\
.25 \\
.29 \\
.07 \\
.05 \\
.07 \\
.11 \\
.01 \\
.02 \\
.04 \\
.06\end{array}$ & $\begin{array}{l}3 \\
3 \\
3 \\
3 \\
4 \\
4 \\
4 \\
4 \\
5 \\
5 \\
5 \\
5\end{array}$ & $\begin{array}{l}1 \\
2 \\
3 \\
4 \\
1 \\
2 \\
3 \\
4 \\
1 \\
2 \\
3 \\
4\end{array}$ \\
\hline \multicolumn{8}{|c|}{ TRIANGULAR PULSE } \\
\hline $\begin{array}{r}1.014 \\
1.014 \\
1.014 \\
1.014 \\
0.338 \\
.338 \\
.338 \\
.338 \\
.203 \\
.203 \\
.203 \\
.203\end{array}$ & $\begin{array}{r}0 \\
0.4 \\
.7 \\
1.0 \\
0 \\
0.4 \\
.7 \\
1.0 \\
0 \\
0.4 \\
.7 \\
1.0\end{array}$ & $\begin{array}{r}0.51 \\
.00 \\
-.20 \\
-.32 \\
.17 \\
.00 \\
-.06 \\
-.11 \\
.10 \\
.00 \\
-.04 \\
-.07\end{array}$ & $\begin{array}{r}1.29 \\
0.56 \\
.51 \\
.57 \\
.43 \\
.18 \\
.17 \\
.22 \\
.25 \\
.11 \\
.10 \\
.13\end{array}$ & $\begin{array}{r}1.29 \\
0.21 \\
.20 \\
.32 \\
.43 \\
.06 \\
.06 \\
.12 \\
.25 \\
.03 \\
.04 \\
.07\end{array}$ & $\begin{array}{r}0.15 \\
.21 \\
.22 \\
.25 \\
.04 \\
.07 \\
.08 \\
.08 \\
.01 \\
.04 \\
.05 \\
.07\end{array}$ & $\begin{array}{l}6 \\
6 \\
6 \\
6 \\
7 \\
7 \\
7 \\
7 \\
8 \\
8 \\
8 \\
8\end{array}$ & $\begin{array}{l}1 \\
2 \\
3 \\
4 \\
1 \\
2 \\
3 \\
4 \\
1 \\
2 \\
3 \\
4\end{array}$ \\
\hline \multicolumn{8}{|c|}{ SQUARE PULSE } \\
\hline 1.014 & 0 & 1.00 & 1.00 & 1.00 & 0.04 & 9 & 1 \\
\hline 1.014 & 0.4 & 0.25 & 1.00 & 0.49 & .19 & 9 & 2 \\
\hline 1. 014 & .7 & .05 & 1.00 & .53 & .22 & 9 & 3 \\
\hline 1. 014 & 1.0 & -.01 & 1. 00 & .50 & .28 & 9 & 4 \\
\hline 0.334 & 0 & 1.00 & 1. 00 & 1. 00 & .01 & 10 & 1 \\
\hline .334 & 0.4 & 0.25 & 1. 00 & 0.50 & .06 & 10 & 2 \\
\hline .334 & .7 & .05 & 1. 00 & .50 & .08 & 10 & 3 \\
\hline .334 & 1.0 & .00 & 1.00 & .50 & .10 & 10 & 4 \\
\hline .203 & 0 & 1.00 & 1. 00 & 1.00 & .02 & 11 & 1 \\
\hline .203 & 0.4 & 0.25 & 1. 00 & 0.50 & .03 & 11 & 2 \\
\hline .203 & .7 & .05 & 1. 00 & .50 & .04 & 11 & 3 \\
\hline .203 & 1.0 & .00 & 1. 00 & .50 & .06 & 11 & 4 \\
\hline
\end{tabular}

tion $a$. In many cases, however, the coincidence can be markedly improved by considering the response curves to be shifted a small distance to the left. They can also be improved, in those cases where oscillatory response is present, by fairing a line through the oscillatory response. Both of these methods of record improvement are commonly employed.

The errors of the various accelerometers for the acceleration pulses considered are given in table 1 . In columns 1 and 2 , respectively, are given the accelerometer characteristics: $R$, ratio of natural period to pulse duration; and $D$, ratio of damping constant to critical value.

In column 3, table 1 , is given the difference between the maximum value of dimensionless response, $\xi$, and the maximum value of the dimensionless applied acceleration, $a$. The error varies from 0 to 100 percent.
In column 4 , table 1 , is given the largest absolute value of the difference $\xi-a$ where $\xi$ and $a$ are evaluated at the same dimensionless time. The error varies from a minimum of 10 percent to a maximum of 136 percent.

In column 5 , table 1 , is given the largest absolute value of the difference $\xi-a$ after shifting the $\xi$ curve to the left by the amount $\Delta \tau$ given in column 6 . The error in this case is typical of the usual way of interpreting accelerometer records. This error varies from a minimum of 3 percent to a maximum of 136 percent. If only accelerometers with damping are considered $(D>0)$, the largest error is 32 percent when the accelerometer is subjected to accelerat on pulses of triangular or sinusoidal time his tories.

On the basis of the few cases investigated, an optimum value of damping is indicated to be between 0.4 and 0.7 of the critical value. It is also indicated that, to obtain an accuracy of better than 5 percent of the peak acceleration in measuring acceleration pulses having the general characteristics of the triangular or sinusoidal pulses, an accelerometer must have a natural period of less than about one-third the duration of the acceleration pulse.

Acknowledgment is due to the Bureau of Aeronautics, Navy Department, whose research projects on vibration pickups have provided the impetus for the work presented in this paper. The authors also extend thanks to L. W. Roberson and I. Smith for assistance in computing the many response curves and preparing the figures and table.

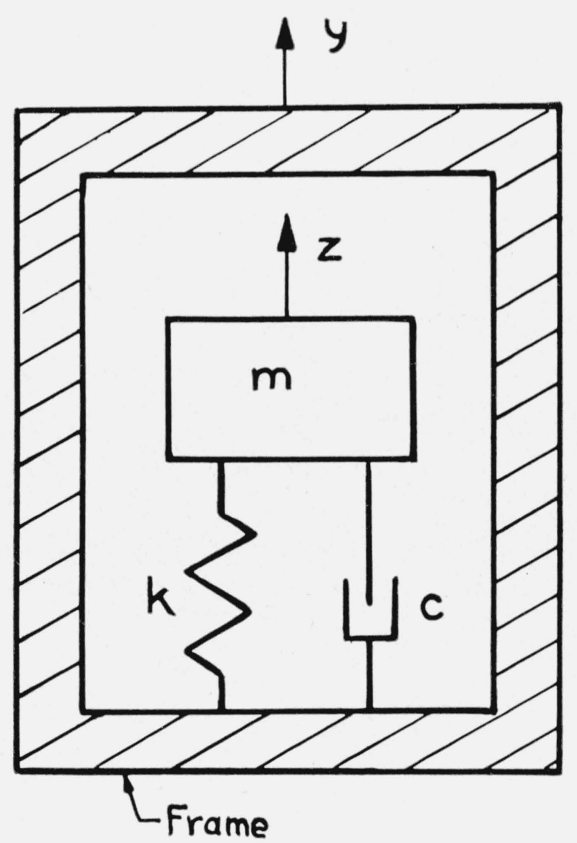

Figure 1. Single-degree-of-freedom system representing accelerometer.

Displacement of frame is $y$, displacement of internal mass is $z$, relative displace. ment of internal mass with respect to frame is $x=z-y$. 


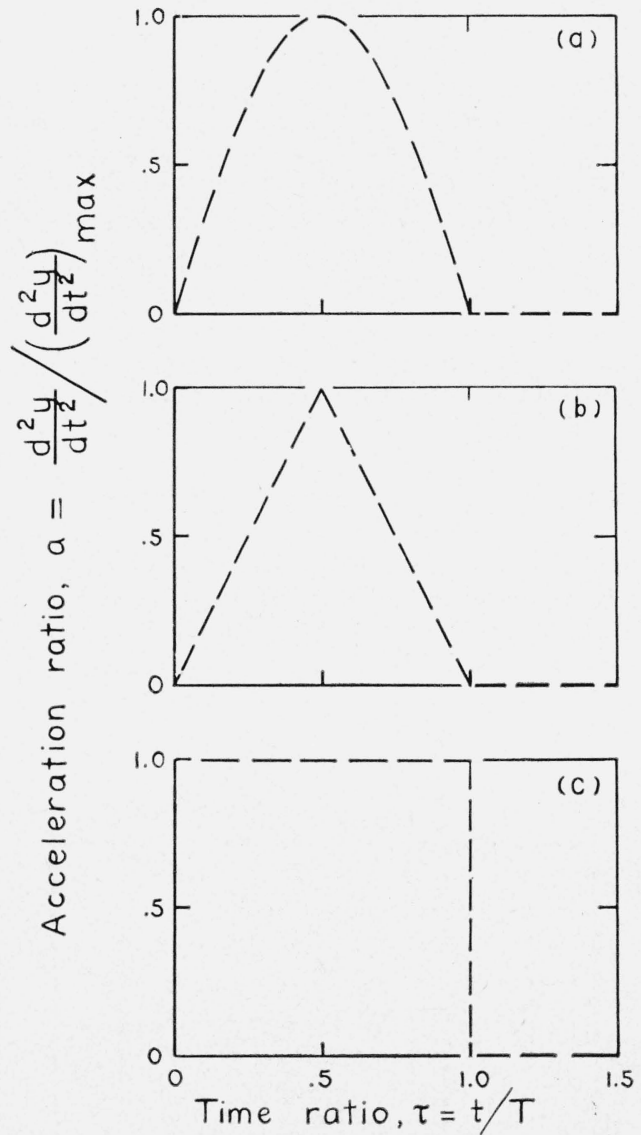

FIGURE 2. Pulses of acceleration for which integration was carried out: (a) half-sine-wave pu!se, (b) triangular pulse, (c) square pulse.

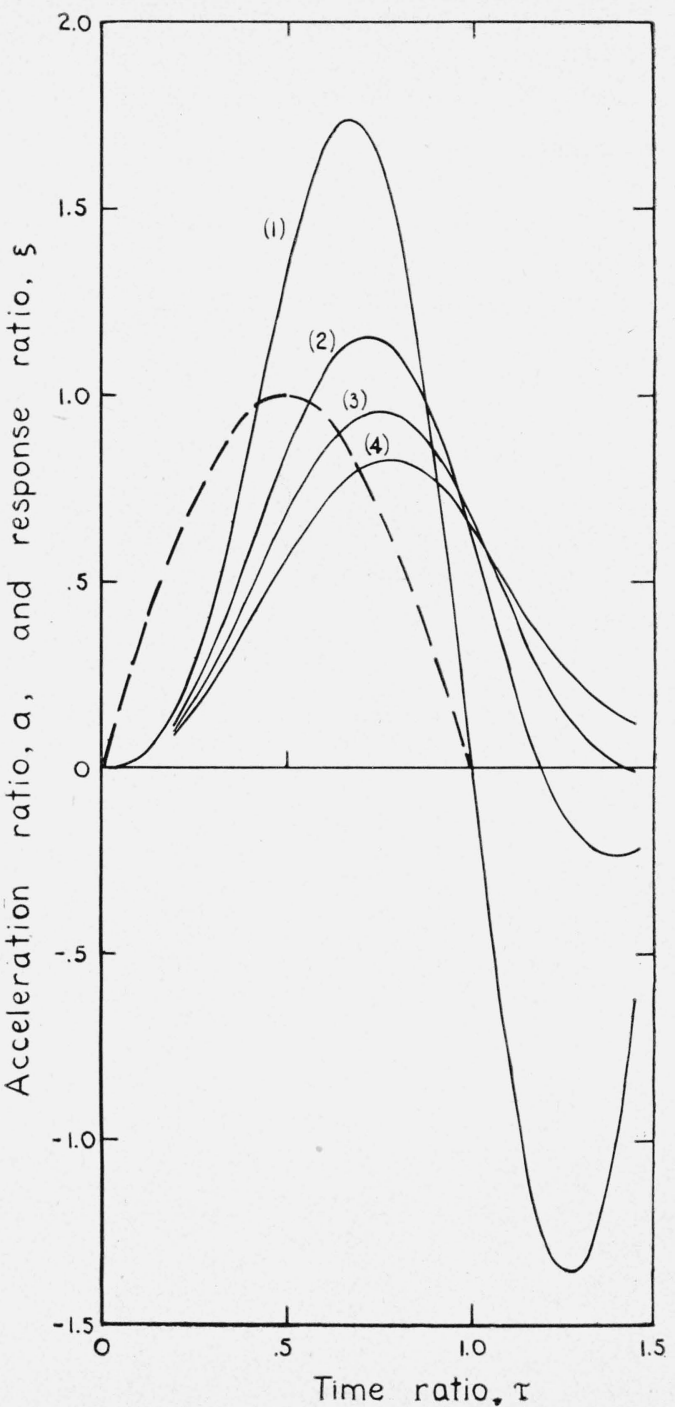

Figure 3. Response to a half-sine-wave pulse of acceleration, dashed curve of an accelerometer whose natural period is about equal to the duration of the pulse, $R=1.014$.

Curve (1), damping coefficient zero, $D=0$; curve (2), damping coefficient 0.4 of the critical, $D=0.7$; curve (4), damping coefficient equal to the critical, $D=1.0$. 


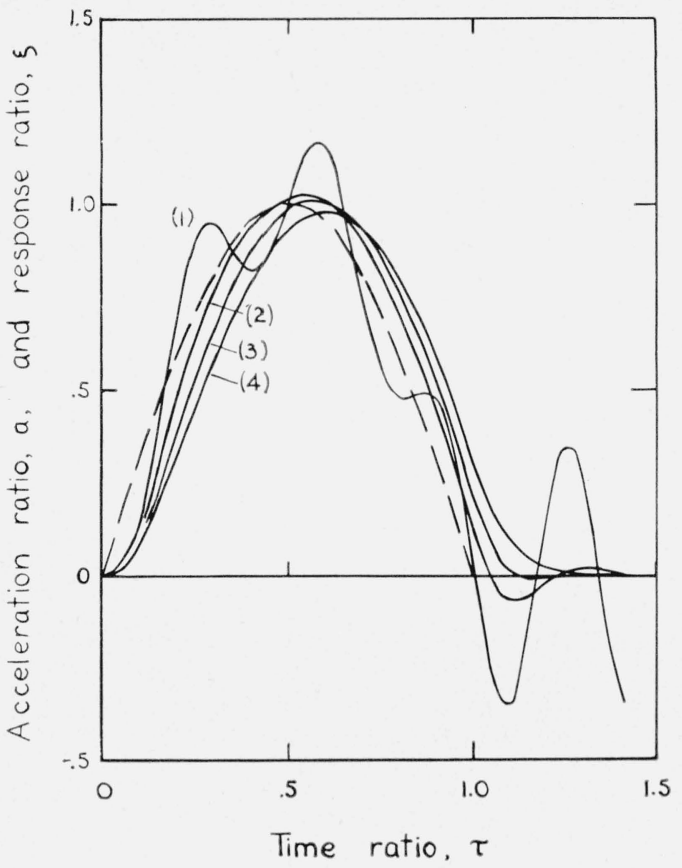

FIGURE 4. Response to a half-sine-wave pulse of acceleration, dashed curve, of an accelerometer whose natural period is about equal to one-third of the duration of the pulse, $R=0.338$.

Curve (1), damping coefficient zero, $D=0$; curve (2), damping coefficient 0.4 of the critical, $D=0.4$; curve (3), damping coefficient 0.7 of the critical, $D=0.7$; curve (4), damping coefficient equal to the critical, $D=1.0$.

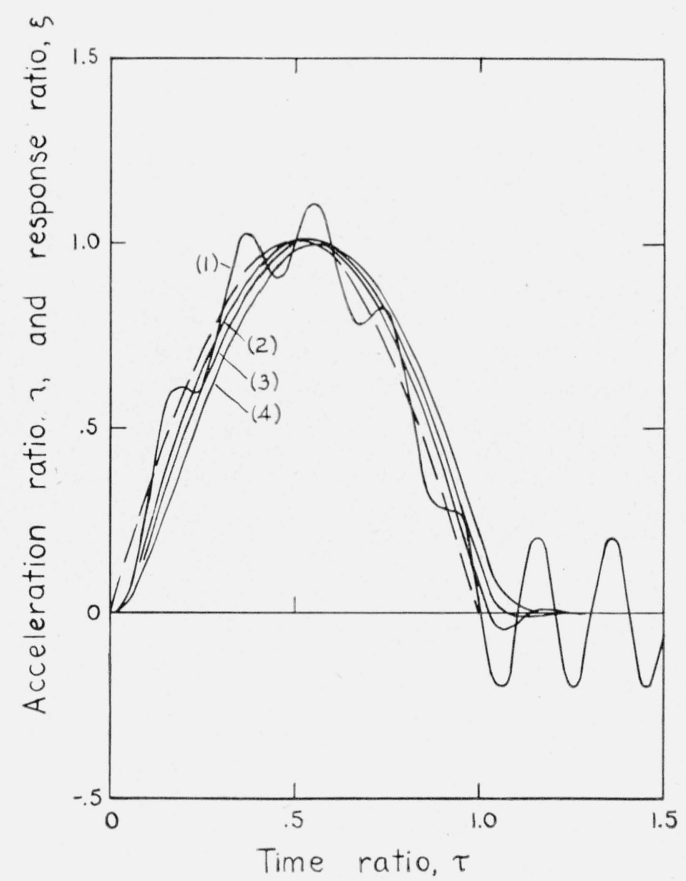

Figure 5. Response to a half-sine-wave pulse of acceleration, dashed curve, of an accelerometer whose natural period is about equal to one-fifth of the duration of the pulse, $R=0.203$.

Curve (1), damping coefficient zero, $D=0$; curve (2), damping coefficient 0.4 of the critical, $D=0.4$; curve (3), damping coefficient 0.7 of the critical, $D=0.7$; curve (4), damping coefficient equal to the critical, $D=1.0$.

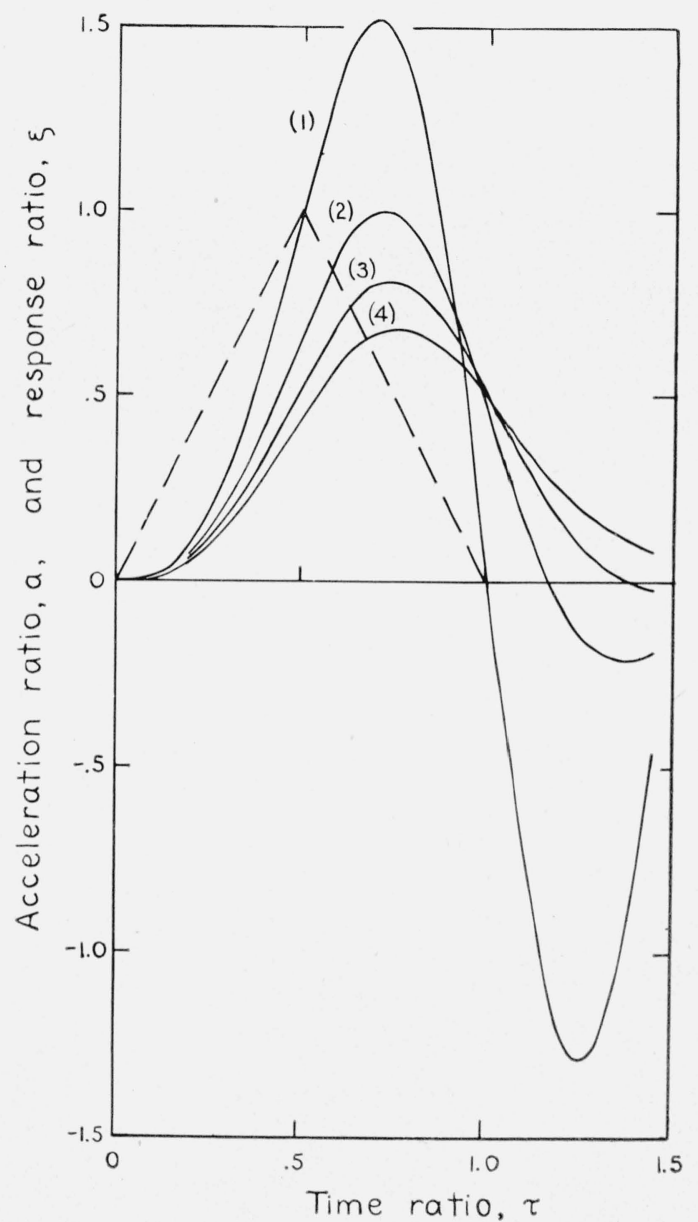

FIGURE 6. Response to a triangular pulse of acceleration, dashed curve, of an accelerometer whose natural period is about equal to the duration of the pulse, $R=1.014$.

Curve (1), damping coefficient zero, $D=0$; curve (2), damping coefficient 0.4 of the critical, $D=0.4$; curve (3), damping coefficient 0.7 of the critical, $D=0.7$; curve (4), damping coefficient equal to the critical, $D=1.0$.

307 


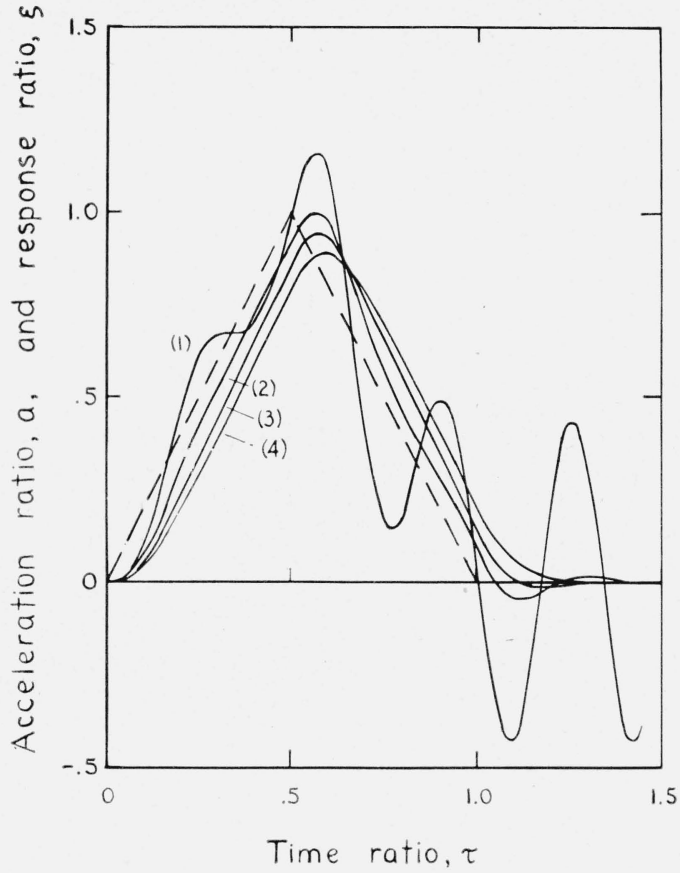

FIGURE 7. Response to a triangular pulse of acceleration, dashed curve, of an accelerometer whose natural period is about equal to one-third of the duration of the pulse, $R=0.338$.

Curve (1), damping coefficient zero, $D=0$; curve (2), damping coefficient 0.4 of the critical, $D=0.4$; curve (3), damping coefficient 0.7 of the critical, $D=0.7$; curve (4), damping coefficient equal to the critical, $D=1.0$.

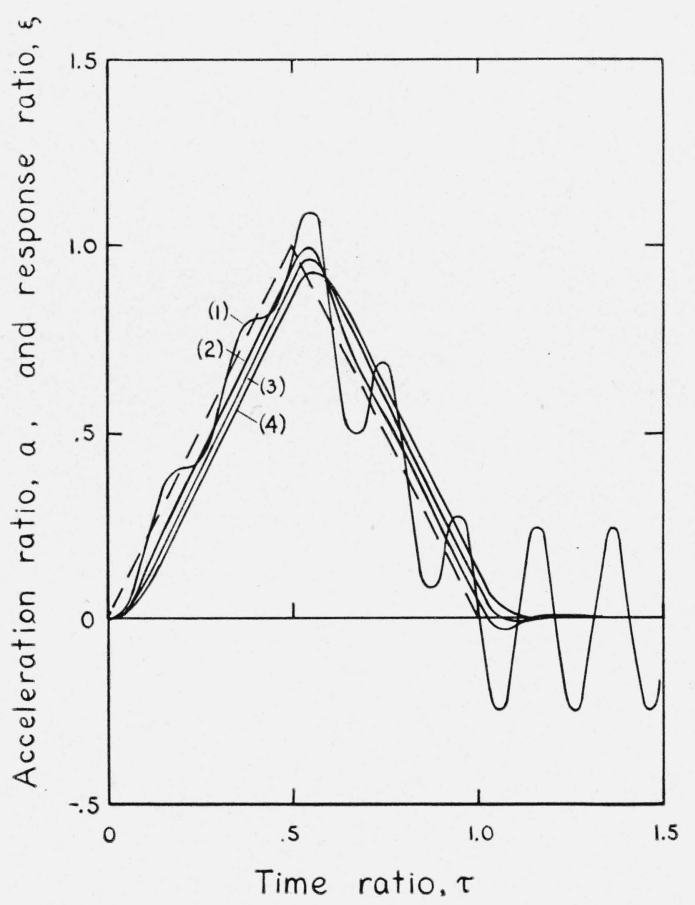

FIgURE 8. Response to a triangular pulse of acceleration, dash curve, of an accelerometer whose natural period is about equal to one-fifth of the duration of the pulse, $\mathbf{R}=0.203$.

- Curve (1), damping coefficient zero, $D=0$; curve (2), damping coefficient 0.4 of the critical, $D=0.4$; curve (3), damping coefficient 0.7 of the critical, $D=0.7$ curve (4), damping coefficient equal to the critical, $D=1.0$.

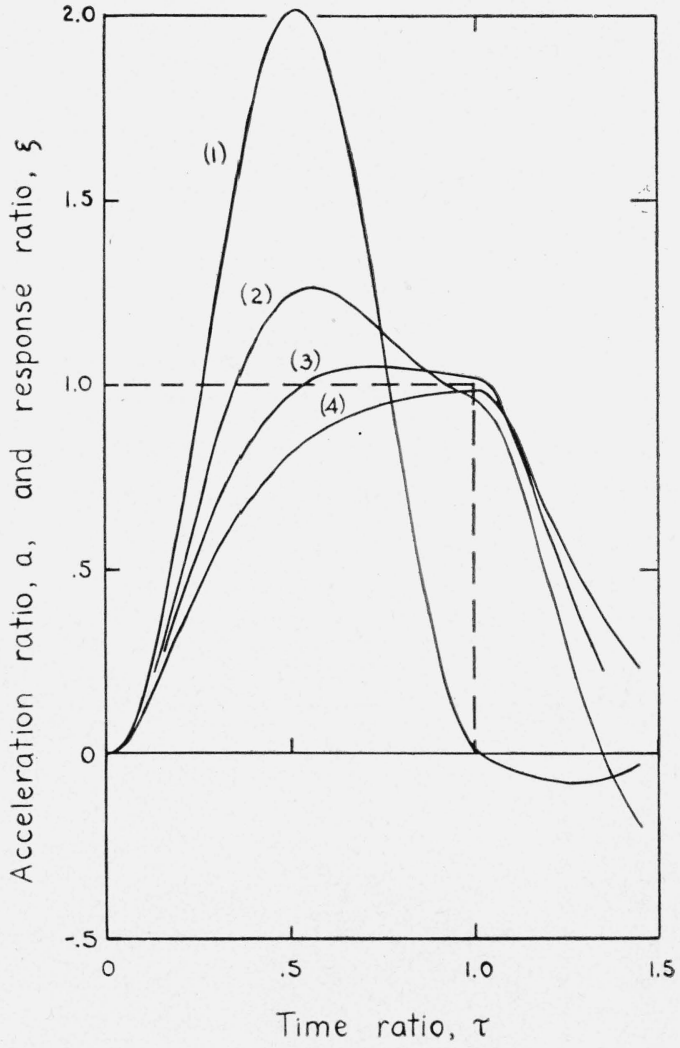

FIgure 9. Response to a square pulse of acceleration, dashed curve, of an accelerometer whose natural period is about equal to the duration of the pulse, $R=1.014$.

Curve (1), damping coefficient zero, $D=0$; curve (2), damping coefficient 0.4 of the critical, $D=0.4$; curve (3), damping coefficient 0.7 of the critical, $D=0.7$; curve (4), damping coefficient equal to the critical, $D=1.0$. 


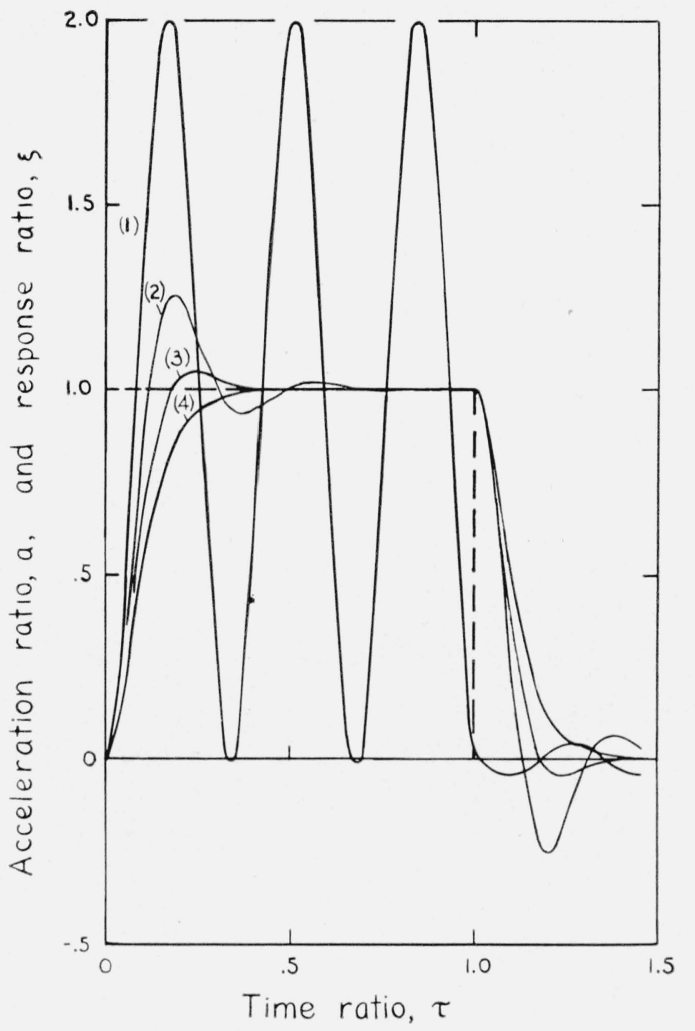

FIGURE 10. Response to a square pulse of acceleration, dashed curve, of an accelerometer whose natural period is about equal to one-third of the duration of the pulse, $R=0.334$.

Curve (1), damping coefficient zero, $D=0$; curve (2), damping coefficient 0.4 of the critical, $D=0.4$; curve (3), damping coefficient 0.7 of the critical, $D=0.7$ curve (4), damping coefficient equal to the critical, $D=1.0$.

\section{References}

[1] J. P. Den Hartog, Mechanical vibrations (McGraw-Hill Book Co., Inc. New York, N. Y., 1940).

[2] D. E. Weiss, Design and application of accelerometers, Proc. SESA, vol. IV, no. II, p. 89 (1947).

[3] W. P. Welch, A proposed new shock measuring instrument, Proc. SESA, vol. V, no. I, p. 39 (1947).

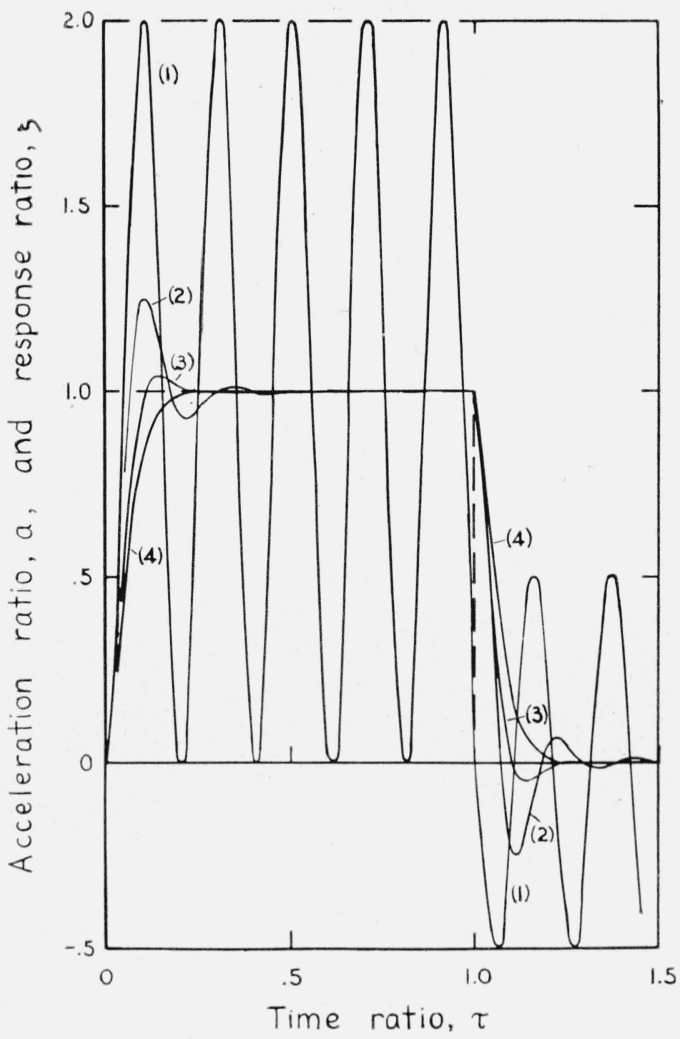

FIGURE 11. Response to a square pulse of acceleration, dashed curve, of an accelerometer whose natural period is about equal to one-fifth of the duration of the pulse, $R=0.203$.

Curve (1), damping coefficient zero, $D=0$; curve (2), damping coefficient 0.4 Curical, $D=0.7$; curve (4), damping coefficient equal to the critical, $D=1.0$.

[4] J. M. Frankland, Effects of impact on simple elastic structures, Taylor Model Basin Rep. 481 (April 1942).

[5] M. A. Biot and R. L. Bisplinghoff, Dynamic loads on airplane structures during landing, NACA ARR No. 4H10 (Oct. 1944).

Washington, May 11, 1950. 